\title{
High Temperature Tests for Graphite Materials
}

\author{
E.I. Zhmurikov
}

Budker Institute of Nuclear Physics SB, Russian Academy of Sciences, Russia

Copyright $\mathrm{O} 2016$ by authors, all rights reserved. Authors agree that this article remains permanently open access under the terms of the Creative Commons Attribution License 4.0 international License.

\begin{abstract}
A lot of researchers analyzed reasons for the destruction of the reactor graphite under intense flux of radiation and high temperatures. However, typically, this analysis does not go beyond operating temperatures of graphite reactors that is as usually $800^{\circ} \mathrm{C}$ about. In this paper we consider the possibility to predict the life-time of reactor graphite at high temperatures $\left(\sim 2000^{\circ} \mathrm{C}\right)$ in principle. Presently appears that the major parameters that affect to the graphite lifetime are the temperature and heating time. High temperature tests were conducted to simulate the heating under the influence of a beam of heavy particles by passing through the sample pulse or AC to study laws of the destruction of a graphite target. Tests carried out in this work have shown the ability to forecast the stability and durability of graphite materials that traditionally used in nuclear engineering at high temperature conditions.
\end{abstract}

Keywords Structure and Properties of Carbon, Graphite Lifetime, Radioactive Ion Beams

\section{Introduction}

This study was performed within the framework of the EURISOL for facilities SPIRAL-II (GANIL, France) and SPES (LNL, Italy) [1-4], and aims to investigate the anticipated strength properties of fine-grained graphite at elevated temperatures. It appears that the major parameters that affect to the lifetime of a graphite target of this IP are the temperature and heating time. High temperature tests were conducted to simulate the heating under the influence of a beam of heavy particles by passing through the sample pulse or AC to study laws of the destruction of a graphite target. Tests carried out in this work have shown the ability to forecast the stability and durability of graphite materials that traditionally used in nuclear engineering at high temperature conditions [5].

The strength and durability of graphite is directly related to the micro - and mesostructure carbon composite material, as well as characteristics such as density and anisotropy, crystallite size, pore size and its nature, i.e. with the material structure in the wide sense of the word. The strength change of the material occurs when there are significant modifications of its phase composition, microstructure and/or a porous structure. In other words, when there are phase transformations processes, sintering, recrystallization, formation or healing of defects, all of these processes together, or at least one of them [6].

The foregoing suggests the necessity for the studies of the graphite material structure and defects to forecast the lifetime of its operability on the basis of the most common reasons of structural- analytical theory of strength. Thus, in particular, more than important is the question about the interrelated phenomena of the strength, creep, and the self-diffusion. It should be noted that in the graphite composites, as well as in the metals the role of the intergrain boundary is very significant. Thus, in particular, for metals have been shown [7] that this creep activation energy close to the activation energy of a self-diffusion, under certain conditions may become the controlling mechanism of the energy dissipation.

Earlier, a number of works, such as the review of the [8] were analyzed reasons for the destruction of the reactor graphite under intense flux of radiation and high temperatures. However, typically, this analysis does not extend operating temperatures of graphite reactors that is usually $800^{\circ} \mathrm{C}$ about. In this paper we consider the possibility to predict the life-time of reactor graphite at high temperatures $\left(2000^{\circ} \mathrm{C}\right)$ in principle. In addition; we are trying to understand the possible reasons for differences in graphite lifetime of various grades.

\section{Samples and Experimental Method}

For the tests are used fine-grained graphite made by German company of Carbon Group (SGL brand) [9], as so from French company Le Carbone-Lorraine (LeCL) [10] and graphite of MPG brand from Russian firm NEP [11]. Table.1 presents the graphite specifications of SGL, LeCL and MPG grade.

Samples of the size $65 \times 5 \times 1 \mathrm{~mm}$ were heated with alternating current in a vacuum $2 \times 10^{-4}$ Torr, the temperature of the samples was measured by the pyrometer IS12 from «Impac electronics». The special design of the 
holder was used to eliminate the mechanical stress of samples in test time. For fixing the graphite samples were developed special clips from tantalum that not only withstand high temperatures without oxidizing, but also allow creating the reliable current leads [12].

Table 1. Graphite samples features

\begin{tabular}{|c|c|c|c|c|}
\hline & $\begin{array}{c}\text { Unit of } \\
\text { measure }\end{array}$ & $\begin{array}{c}\text { SGL } \\
\text { Carbon } \\
\text { Group }\end{array}$ & $\begin{array}{c}\text { LE Carbone } \\
\text { Lorraine }\end{array}$ & MPG-6 \\
\hline $\begin{array}{c}\text { Volumetric } \\
\text { density }\end{array}$ & $\mathrm{g} / \mathrm{cm}^{3}$ & $1,73-1,82$ & 1,86 & $1.76-1.88$ \\
\hline $\begin{array}{c}\text { Specific } \\
\text { electric } \\
\text { resistance }\end{array}$ & $\mathrm{MkOm} \mathrm{m}$ & $9,4-10,2$ & 16 & $11-16$ \\
\hline $\begin{array}{c}\text { Bending } \\
\text { strength }\end{array}$ & $\mathrm{MPa}$ & $40-85$ & - & $50-70$ \\
\hline $\begin{array}{c}\text { Compressive } \\
\text { strength }\end{array}$ & $\mathrm{MPa}$ & $90-170$ & 76 & $100-120$ \\
\hline Porosity & $\%$ & $9,5-15$ & 6 & 9 \\
\hline Ash content & $\%$ & $<0,03$ & - & $0,25-0,1$ \\
\hline $\begin{array}{c}\text { Grain size } \\
\text { Young's } \\
\text { modulus }\end{array}$ & $\mathrm{mkm}$ & $<3-20$ & 5 & $30-150$ \\
\hline $\begin{array}{c}\text { Thermal } \\
\text { conductivity }\end{array}$ & $\mathrm{Wt} / \mathrm{m}^{*} \mathrm{~K}$ & $65-130$ & 80 & $180-190$ \\
\hline $\begin{array}{c}\text { Thermal } \\
\text { expansion } \\
\text { coefficient }\end{array}$ & $10^{-6} \mathrm{~K}^{-1}$ & $3,5-5,8$ & 5,7 & $-8,8$ \\
\hline
\end{tabular}

In this design, the graphite sample holder provides freedom of rotation in the attachment points at the ends of the graphite sample, nearly spherical bearings. On the basis of these clips were designed same fastenings, which allowed applying an adjustable load onto the sample. High-temperature test with high-load are shown appreciable decrease of the sample lifetime during the test, depending on the magnitude of the applied load. However, the results of these tests were very preliminary and their analysis was not carried.

\section{X-Ray Measurements}

X-Ray measurements were carried out on the URD-6 with monochromatic $\mathrm{CuK \alpha}$-radiation [13]. The registration of diffractograms was performed in steps mode with step $0.05^{\circ}$, the accumulation time is 10 seconds and the angle range $2 \theta$ was since 10 to $100^{\circ}$. These measurements show that the on X-ray graphite patterns SGL, LeCL and MPG are almost all reflections which typical for graphite of $2 \mathrm{H}$ polytypic (fig.1)

However, the expansion of these reflexes is very different, and narrow reflex type $00 l$ and $h k 0$ testify about the relatively large size of coherent scattering regions (CSR). Periodic structure in this region is stored as in the direction that perpendicular to the graphite layers and so in the layer plane. A significant broadening of the peaks with $h k l$ indices means that the graphite structure is stored a large number of stacking faults and/or alternating layers errors. From X-ray diffractogram can be estimated as interplanar distances and so the magnitude of a coherent scattering region by Williamson-Hall method.

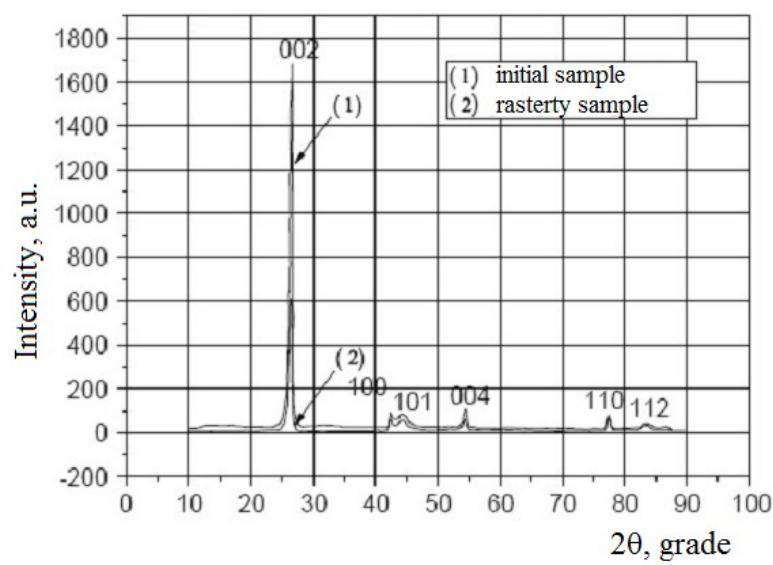

Figure. 1. The X-Ray diagram of fine dense graphite SGL brand. Curve (1) refers to the unbroken plate, curve (2) to the grinded sample. The height of the 002 peak is much larger in the first case, because the sample has a texture - in the 001 direction take a place the preferential orientation. X-ray diagrams for graphite samples of LeCL and MPG-6 brand are identical to the lower curve.

Table 2. Crystallographic parameters of graphite composites

\begin{tabular}{|c|c|c|c|c|c|}
\hline \multirow{2}{*}{ Sample } & \multicolumn{2}{|c|}{$\begin{array}{l}\text { The lattice } \\
\text { parameters }\end{array}$} & \multicolumn{2}{|c|}{ The CSR size, $\AA$} & \multirow{2}{*}{$\begin{array}{c}\text { The value of } \\
\text { micro } \\
\text { distortions } \\
\Delta \varepsilon_{001}\end{array}$} \\
\hline & $a, \AA$ & $c, \AA$ & 001 & hk0 & \\
\hline MPG-6 & $2.464(1)$ & $6.766(3)$ & $>1500$ & 250 & 0.0065 \\
\hline SGL & $2.465(1)$ & $6.764(4)$ & 300 & 250 & 0.0030 \\
\hline LeCL & $2.463(1)$ & $6,792(5)$ & $>1000$ & 220 & 0.0060 \\
\hline
\end{tabular}

\section{High Temperature Tests for Lifetime Forecast}

The measurement results are shown in Fig. 2. It is clearly seen that the operating temperature of graphite SGL brand can be significantly higher than the brands of the MPG-6 and the LeCL. The latter fact is detailed discussed earlier in [12-14], and it is associated presumably with the structural features of the SGL graphite, in particular with the anisotropy of the material. This anisotropy was confirmed by the X-ray measurements and measurements carried out by scanning electron microscopy. These questions are discussed in details in the second chapter of the monograph $[12,13]$.

Creep of polycrystalline graphite at the high temperature region $\left(2500 \div 3000^{\circ} \mathrm{C}\right)$ is due to the self-diffusion of carbon and depends on the phenomenon of sublimation of graphite by opinion of authors [15]. According to [15] the activation energy for creep in this temperature range is between $720 \div 1130 \mathrm{~kJ} / \mathrm{mol}$, and it is close to the graphite sublimation energy $\Delta H_{\text {subl }} \sim 716,7 \mathrm{~kJ} / \mathrm{mol}$. The activation energy of self-diffusion by [15] can be estimated as $680^{ \pm 50}$ 


\section{$\mathrm{kJ} / \mathrm{mol}$.}

It is obvious that the namely sublimation is the source of vacancies in the crystallites, i.e. the primary cause the vacancy diffusion and consequently the diffusion mechanism of creep at high temperatures. It should be noted that the phenomenon of creep in graphite can be connected with the movement of edge and screw dislocations too. At the same time, at temperatures up to $2500^{\circ} \mathrm{C}$ is quite acceptable explanation of creep in polycrystalline graphite is made by S. Mrozowski and J.E. Hove [15]. In this study the mechanism of creep is occurs because the rupture of peripheral $\mathrm{C}-\mathrm{C}$ bonds, and the crystallites slide relative to each other.

Highly ordered graphite is characterized by a melting enthalpy $\Delta H_{m}$ is equal to $\sim 104 \mathrm{~kJ} / \mathrm{mol}$, the enthalpy of combustion $\Delta H_{\text {comb }}$ is equal to $\sim 395 \mathrm{~kJ} / \mathrm{mol}$ [16]. The latest roughly corresponds to the energy of $\sigma$-bond for graphite that equals to $418,7 \div 460,6 \mathrm{~kJ} / \mathrm{mol}$ [17]. Initially, the activation energy of destruction of MPG-6 obtained from the data [18] was estimated by value about $890 \mathrm{~kJ} / \mathrm{mol}$. This value is considerably higher than one for the sublimation energy, and can be corresponds the energy of creep, for example, what agrees with data $[15,16]$. The creep energy can be reaching a value up to $\sim 1200 \mathrm{~kJ} / \mathrm{mol}$ by [15]. However, a more accurate set up of the experiment shows significantly lower activation energy of the destruction process for the MPG-6. These values are equal about $690^{ \pm 60}$ $\mathrm{kJ} / \mathrm{mol}$ both for MPG-6 and LeCL graphite brands. This quantity is already very close to the energy of sublimation of graphite $716,7 \mathrm{~kJ} / \mathrm{mol}$ [16] or more likely to the activation energy of self-diffusion of carbon in graphite.

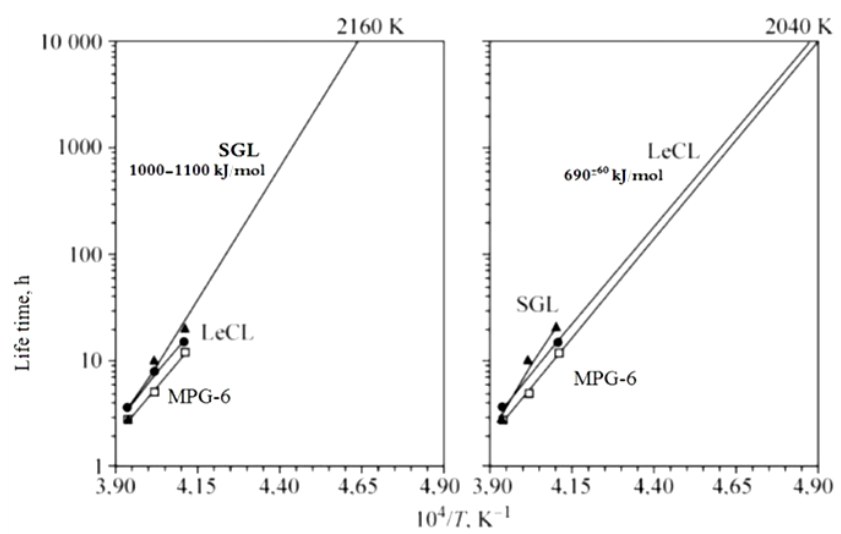

Figure. 2. The dependence of the lifetime of the samples SGL, MPG-6 and LeCL in Arrhenius coordinates: on the left - SGL; on the right - LeCL and MPG.

We can presume from to the obvious circumstance that, according to [15] "...in the conditions of high temperatures the hypothesis of S. Mrozowski\&J.E. Hove is valid". This hypothesis is related with influence of the anisotropy of polycrystalline to the temperature dependence of the strength and elasticity.

The increase the strength of graphite and its elastic modulus with increasing temperature up to $\sim 2500^{\circ} \mathrm{C}$ according to this hypothesis can be explained by two factors:
- intrinsic anisotropy of individual crystallites of graphite;

- $\quad$ polymeric nature of intergranular valence bond.

One can also guess that a significant expansion of the crystallites in the selected direction of the $c$-axis results into an intercrystallite voids and this compression of grains makes the structure more rigid. Obvious disadvantage of this explanation is connected with the fact that in boron nitride an increasing the ultimate strength with temperature is not occurs, although this material is very close by its structural properties to graphite.

Contrary to strength hypothesis, H.E. Martens [15] had suggested that the increase in graphite strength under high temperatures is due to the decrease stress concentration through the plastic deformation. The latter idea is in good agreement with the ideology of physical mesomechanics where accommodative processes occur as a result shift and rotary modes of deformation [19].

\section{High-resolution Scanning Electron Microscopy}

Graphite of the SGL brand according to the high-resolution scanning electron microscopy has a distinguished anisotropy of the structure (fig. 3, 4). This anisotropy supposedly connected by using of needle coke with a grain size of $20-30 \mathrm{mkm}$ as a base material of graphite composite. The particles of coke are produced in grinding process with high anisometric, and pressing this powder into a matrix one can be obtained artificial graphite with high density, but combined with a very high and undesirable anisotropy of physical and mechanical properties. Direct confirmation of such anisotropy is an X-ray phase diagram for SGL graphite (fig. 1). The picture of graphite samples MPG and LeCL made in the destruction zone are shown on the fig. 5. The inset in this case at the upper right corner shows the photo of the original surface.

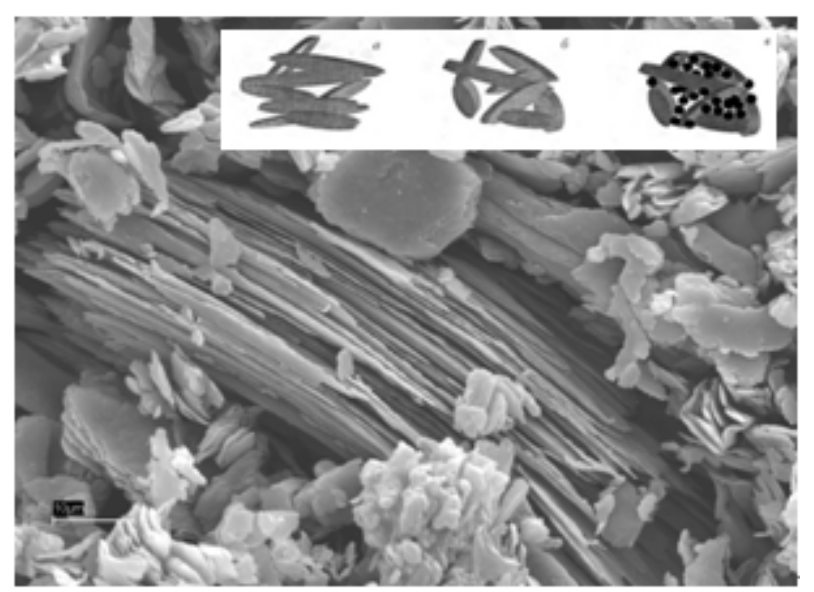

Figure 3. Scanning electron micrographs of the surface of the sample graphite grade SGL in the destruction zone. Inset top is shown particle packing of anisometric filler at different ways of pressing. 


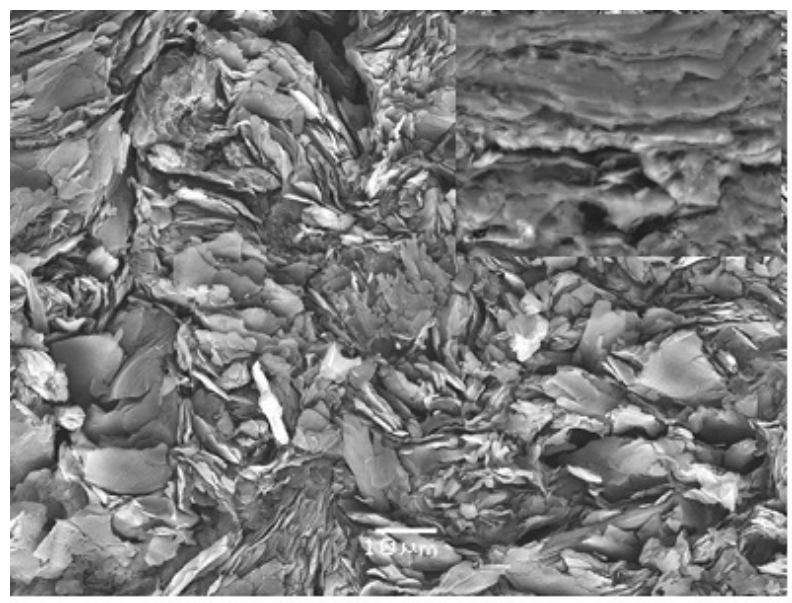

Figure 4. Scanning electron micrographs of the SGL graphite surface. The picture of sample was made a little away from the destruction area in the "secondary electrons" mode. Inset is shown the original surface of the sample; the picture was made in the backscattering mode.
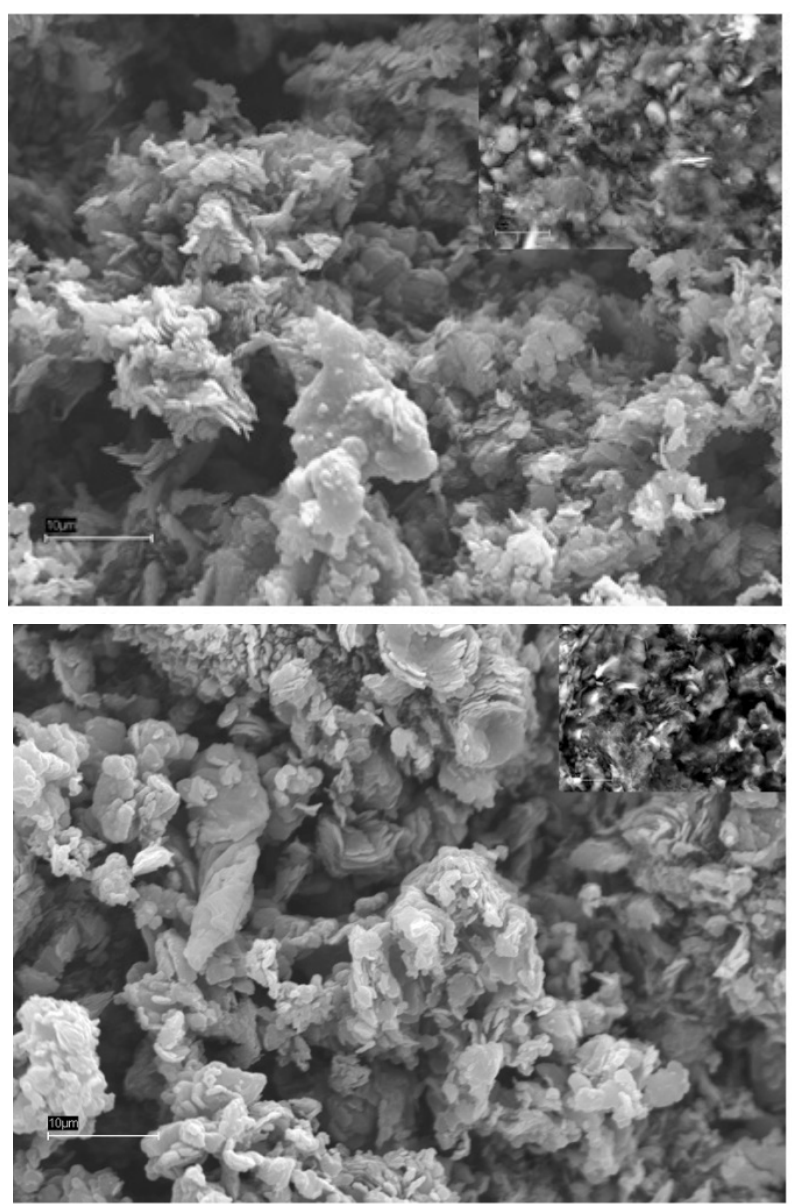

Figure 5. Scanning electron micrographs of the MPG-6 (left) and LeCL (right) graphite surface. The pictures of samples are made in the destruction area in the "secondary electrons" mode. Gold film was evaporating on the sample surface with thick about $100 \AA$. Inset is shown the original surface of samples, the picture was made in the backscattering mode.

\section{Creep Mechanism of Destruction}

Data of [15] suggests, that the creep mechanism in region of low deformation includes itself the crystallites shift when one crystalline packs slides relative to other with limited velocity. In this case the peripheral $\mathrm{C}-\mathrm{C}$ bonds are permanently ruptured and restores. At the same time, a comparison of the average activation energy of graphite creep with a value of $680^{ \pm 50} \mathrm{~kJ} / \mathrm{mol}$ for the volumetric carbon self-diffusion suggests that the rate of creep at high temperatures is limited by diffusion processes. The recently include itself the movement of atoms at the boundary of grains or crystallites.

The analysis carried out in [20] also showed that the processes of deformation and destruction of polycrystalline graphite basically pass along grain boundaries. This was discovered in study of the destruction process as before of loading and so after the stress removing. The destruction occurs through a coke binder by means of development and integration of already existing cracks and pores. However, if in the initial grains have an oriented small cracks, the main crack can freely cross these grains. In the supercritical state of disintegration, when the speed of spread of the main crack under tension is high, the main crack also can cross the individual grains.

Basically, the main crack, avoiding macroscopic grain extends in micro-volume generally parallel to the basal planes of the crystal, splitting weak links so that the destruction occurs mainly on the boundaries of the misoriented crystallites. Though macro-cracks may cross as individual crystallites and so macroscopic grains, but such a character of the destruction is not a major. The smaller the diameter of the crystallites, the more difficult of the main crack spread, hence as a result is more high strength of fine-grained materials.

\section{Conclusions}

This study shows that the kinetics of destruction of graphite composites at high temperatures generally in good agreement with the thermofluctuational concept of solids state destruction. It was also found that the activation energy of the fracture can be associated with the creep phenomena of carbon, where important role plays features of graphite mesostructure and the anisotropy of the material.

\section{Acknowledgements}

Author is grateful to prof. L.B. Zuev and prof. Y.P. Sharkeev (ISPMS SB RAS) for unchanging attention and interest to the study; as well as laboratory assistants, technicians and engineers of BINP SB RAS, in particular, I.E. Jul, N.H.Cot, M.A. Blinov; all others who helped in the measurement and testing of the graphite samples; A.T. Titov (IGM SB RAN) for the electron-scanning microscopy and prof. S.V. Tsybulya for X-ray measurements. 


\section{RERERENCES}

[1] The Eurisol Project: http://www.eurisol.org/

http://www.cl-brakes.com/catalogues/auto.php

[2] SPES project strategy. Accelerators at LNL Laboratori Nazionali di Legnaro: http://www.indiana.edu/ lens/UCANS/Meetings/UCANSII/ PDF_presentations/UCANS_II_Prete_Thurs_10_55.pdf

[3] System for Producing Online Accelerated Radioactive Ions. France:

http://www.ganil-spiral2.eu/science-us/accelerator/spiral

[4] R. Beunard., at al. Survey and alignment concept for installation of the SPIRAL 2 accelerator devices at GANIL // Proceedings of the 10th International Workshop on Accelerator Alignment, KEK, Tsukuba, 2008.

[13] Zhmurikov E. Mesostructure of graphite composite and its lifetime (engl) // http://arxiv.org/abs/1510.03070

[14] Avilov M.S., Tecchio L.B., Titov A.T., Tsybulya V.S., Zhmurikov E.I. Design of the $50 \mathrm{~kW}$ neutron converter for SPIRAL2 facility // Nuclear Instruments and Methods in Physics Research A. 2010. V.618. p 1-15

[15] Графит как высокотемпературный материал. - Сборник статей // пер. с англ. под ред. К.П. Власова, М.: Мир. 1964.

[5] ISTC Project \# 2257 // Portal of the International Science and Technology Center: http://www.istc.ru/istc/db/projects.nsf/All/1FDF315D27B25 B27C3256C5B0059D33A?OpenDocument\&lang=Eng

[16] Кнунянц И. Л. (гл. ред.) Химическая энциклопедия: в 5 т. // М: Сов. энц. 1988. Т.1., 623 с.

[6] Zhmurikov E. Graphite in Scince and Nuclear Technology (engl) // http://arxiv.org/abs/1508.01814

[7] Орлов А.Н., Перевезенцев В.Н., Рыбин В.В. Границы зерен в металлах. // М: Металлургия, 1980. 156с.

[8] Kelly B.T. et al. Irradiation Damage in Graphite due to Fast Neutrons in Fission and Fusion Systems. // IAEA-TECDOC-1154. IAEA, Vienna, 2000.

[9] SGL Group. The Carbon Company. Product Catalog: http:// www.sglgroup.com/cms/international/products/product-grou $\mathrm{ps} / \mathrm{gs} / \mathrm{index} \cdot \mathrm{html}$ ?__locale $=\mathrm{en}$

[10] Carbone Lorraine Group. The Carbon Company:

[17] Андреев В.Д. Спонтанная графитизация и термодеструкция алмаза при Т> 2000 К. // Физика твердого тела. 1999. Т.41. В.4. С. 695-701.

[18] Avilov M.S., Antoshin A.V., Gubin K.V., at al. Project of rotating carbon high power neutron target. Conceptual design. // Proc. of PAC-2001. Chicago. IL. 17- 22 June 2001

[19] Йошида С. Физическая мезомеханика как полевая теория // Физическаямезомеханика. 2005. Т. 8. №5. С. 17-22

[20] Виргильев Ю.С., Барабанов В.Н. О механизме разрушения графитовых материалов // Проблемы прочности. 1975. №7. С.96-100 